\title{
A failed attempt to autoshape leverpressing in horses
}

\author{
DONALD M. DOUGHERTY \\ University of Texas Health Science Center, Houston, Texas \\ and \\ PAUL LEWIS \\ Ohio University, Athens, Ohio
}

(Frank Bellezza, Sponsor)

\begin{abstract}
In this paper, we describe a study in which we attempted to autoshape three horses to make a leverpress response. This study was motivated by observations made during earlier studies (Dougherty \& Lewis, 1991b, 1992) in which we observed horses directing consummatory behaviors toward stimuli signaling the availability of reinforcers. The procedure was similar to that of other autoshaping procedures. Horses received forward conditioning trials in which stimuli (an illuminated panel and a retractable response lever) were periodically presented together for 10 sec and followed by a grain reinforcer. Each horse's stall served as an experimental chamber. A response panel was positioned in the stall's doorway, and a computer located nearby controlled and monitored experimental events. Each day, for 14 days, 100 stimulus-reinforcer pairings were presented. Despite 1,400 stimuli-reinforcer presentations, none of the horses were autoshaped. A few possible reasons for these results are discussed.
\end{abstract}

In previous studies with horses (Dougherty \& Lewis, 1991b, 1992), we frequently observed horses developing and maintaining consummatory behaviors directed toward stimuli accompanying the delivery of grain reinforcers. For example, in one experiment during the shaping of a leverpressing response, "horses frequently swayed from side to side in front of the response panel... [and] after the first few grain deliveries, ... . spent a lot of time licking the feed bin and the opening from which the grain was delivered"' (Dougherty \& Lewis, 1992, p. 103). In this experiment, and in others, the first reinforced lever response most often was in the form of a licking response. During the experimental sessions that followed, after the leverpress had been established on intermittent reinforcement schedules, horses would often lick a large illuminated stimulus projected onto a Plexiglas panel located above the response lever. These behaviors are interesting for two reasons: (1) they appeared to develop and be controlled by the stimulus-reinforcer relationships, and (2) the topography of the observed response is similar to those naturally elicited by a food reinforcer. These observations led to the present investigation, in which we tried to autoshape a leverpressing response.

Typically in autoshaping experiments, a discrete stimulus (e.g., a keylight) is periodically presented and followed by a reinforcer (e.g., access to grain). After

This research was carried out while the first author was at Ohio University. Requests for reprints should be sent to $D$. M. Dougherty, Human Behavioral Pharmacology Laboratory, University of Texas Health Science Center, 1300 Moursund Street, Houston, TX 77030. relatively few of these stimulus-reinforcer pairings, some organisms, most often pigeons, begin emitting behaviors directed toward the stimulus. When these behaviors are of a sufficient form and force to trigger a recorded response, they are reinforced and, in turn, quickly come under the control of the contingencies of reinforcement. For example, in the first reported autoshaping experiment, Brown and Jenkins (1968) exposed 36 experimentally naive pigeons to trials in which an 8-sec keylight was followed by a 4-sec access to grain. On average, these trials appeared every $60 \mathrm{sec}$, and after as few as six trials, pigeons began pecking at the keylight.

This original autoshaping experiment spurred other researchers (see Schwartz \& Gamzu, 1977, for a discussion) to demonstrate, with some degree of success, autoshaping with other organisms and with other response topographies. The response that is autoshaped, or the response directed toward the stimulus preceding the reinforcer, often resembles the consummatory response that the reinforcer elicits, with few exceptions (Gamzu \& Schwam, 1974; Schwam \& Gamzu, 1975). There are several examples of this: rats lick and gnaw at response levers (Peterson, Ackil, Frommer, \& Hearst, 1972), pigeons and quail peck at lighted stimuli (Brown \& Jenkins, 1968; Gardner, 1969), dogs lick response keys (Smith \& Smith, 1971), fish exhibit feeding responses to keys (Squier, 1969), and monkeys grasp and bite at levers in a manner similar to normal feeding (Moore, 1973).

This similarity between the topography of the consummatory response and the response directed toward the response manipulandum was found in our previous horse 
experiments, even though we were were not intentionally interested in autoshaping responses. Horses licked and bit at stimuli signaling food. It was this similarity between the two types of responses that led to the present autoshaping experiment.

\section{METHOD}

\begin{abstract}
Subjects
Three quarter horses served as subjects: Sis, a 12-year-old mare; Doc, a 15-year-old gelding; and Chico, a 12-year-old gelding. Prior to the experiment, the horses remained together at pasture, and their diets consisted wholly of pasture grass; during the experiment, and following a gradual introduction of a partial grain diet, the horses were removed from the pasture once a day for an experimental session, during which their diets were supplemented with approximately 1.91 of mixed grain (a highly preferred food).
\end{abstract}

\begin{abstract}
Apparatus
Each horse's stall ( $3.7 \mathrm{~m}$ long, $3.7 \mathrm{~m}$ high, and $1.7 \mathrm{~m}$ wide) served as a testing chamber. A response panel $(59.0 \mathrm{~cm}$ long and $43.0 \mathrm{~cm}$ wide), which the experimenters placed in the stall's doorway $127.0 \mathrm{~cm}$ above the floor (in a corner along the front wall), held three components: a stimulus projector, a retractable response lever, and a grain dispenser. The stimulus projector consisted of a $17.8-\mathrm{cm}$-square opening, centered in the panel, $10.2 \mathrm{~cm}$ from the top. On the front side of this opening was a 6.4-mm-thick shield of white translucent Plexiglas. The Plexiglas could be illuminated from behind by a $60-\mathrm{W}$ light bulb. In the center of the stimulus projector, the retractable response lever (Coulbourn Instruments Model Number E23-05) was located. The lever itself was $3.4 \mathrm{~cm}$ wide, $0.5 \mathrm{~cm}$ thick, and protruded $1.8 \mathrm{~cm}$ from the surface of the lever's housing and required a force of $.20 \mathrm{~N}$ to operate. The grain dispenser, when operated, released grain from behind the panel down a grain chute into a feed bin (falling through a $12.7 \times 6.4 \mathrm{~cm}$ opening in the panel centered $61.0 \mathrm{~cm}$ from the top and $12.7 \mathrm{~cm}$ from the right side of the panel) located in front of the panel. The grain chute, $27.9 \mathrm{~cm}$ in length, was attached to the back of the panel and sloped at a $45^{\circ}$ angle. A flap located near the top of the chute held a charge of grain, which was released by operating a solenoid.

The stimulus projector, retractable lever, and grain dispenser were controlled by an Apple Ile computer equipped with an interfacing system described elsewhere (Dougherty, 1990). This apparatus controlled events and monitored responses during experimental sessions from a
\end{abstract} stall adjacent to the horse being tested.

\section{Procedure}

On 14 consecutive afternoons, the horses received the same experimental routine. At the beginning of the experimental routine, the experimenters collected the horses from a pasture and led them to a barn, where each was secured in its home stall. The horses were tested individually by placing the response panel in the doorway of each stall. After the response panel and computer equipment were in position, the experimental session began after a 5-min time-out period. During a session, 100 autoshaping trials, or stimulus-reinforcer pairings, were presented. On trials in which no lever response was recorded, the stimulus projector was illuminated and the lever was extended simultaneously for $10 \mathrm{sec}$ (the stimulus period). After $10 \mathrm{sec}$ had elapsed, the stimulus projector darkened, the lever retracted, and the reinforcer (approximately $60 \mathrm{ml}$ of mixed grain) followed. On trials in which a leverpress was recorded during the 10-sec stimulus period, the leverpress produced the grain reinforcer; also, the stimulus projector darkened, and the lever retracted, both immediately. Trials were presented on a 45 -sec variable-time schedule; the individual intervals used were calculated from Fleshler and Hoffman's (1962) progression equation. At the end of the experimental routine, after all of the horses had completed a session, the experimenters returned the horses to their pasture. This routine from beginning to end required between 4.5 and $5.0 \mathrm{~h}$ to complete.

While a session was in progress, the experimenters sat in a stall adjacent to the horse being tested. It was from this stall that the experimenters controlled the computer and recorded behavioral observations by looking through small holes in the stall's wall.

\section{RESULTS}

The subjects were not autoshaped after 1,400 stimulus-reinforcer presentations. None of the subjects responded consistently on the response lever. But two specific behavioral observations are worth mentioning. First, both Chico and Sis emitted leverpresses during the first few sessions: Chico emitted responses on Trials 10, 43, $78,123,127$, and 403 , and Sis emitted responses on Trials $34,37,78$, and 502 . Second, after the early sessions, all of the horses exhibited fortuitous or stereotypical behaviors. By Session 5, Chico spent most of his time between reinforcement deliveries with his nose positioned motionless in the bottom of the feed bin; Chico's behavior slowly drifted, and by the end of Session 8 , he frequently grasped the lip of the feed bin with his teeth and shook the apparatus. Sis, on the other hand, exhibited a more interesting behavior. By Session 6, she spent her time between reinforcement deliveries with her nose in the corner of the stall opposite the apparatus. After the grain fell into the feed bin, she walked over and consumed the grain in the feed bin and returned to her corner. After this behavior had been established, it was maintained throughout the remainder of the experiment. Doc exhibited a variety of behaviors during the experiment, which included kicking the response panel, biting the lever of the feed bin and shaking the apparatus, pawing at the ground, and weaving his head back and forth in front of the response panel.

\section{DISCUSSION}

In spite of numerous stimulus-reinforcer pairings, we were unsuccessful in producing an autoshaped leverpress in horses. Even though 2 of the 3 horses activated the lever on several occasions during the first few days, leverpressing was not maintained. Horses did maintain superstitious behaviors, however, throughout most of the experiment. These results as a whole were unexpected, because in previous studies, we frequently observed horses directing consummatory behaviors toward stimuli preceding reinforcers (Dougherty \& Lewis, 1991b, 1992).

There are at least two alternative explanations for our failure to autoshape horses to leverpress. First, and perhaps the most obvious reason, is that the apparatus may have not been physically constructed in a manner that would easily engender autoshaping behaviors. Second, it may be the case that horses cannot be autoshaped, although this explanation seems doubtful given that many other organisms can be autoshaped.

Although the former alternative seems most likely, there are certainly major differences between the pigeon's autoshaped response and other organisms' autoshaped responses. Organisms differ in both their amenability to being shaped and the strength of their acquired response. For example, the pigeon's elicited keypeck is strongly controlled by stimulus-reinforcer pairing and is more reliably produced than are similar procedures used with other organisms. Undoubtedly, these differences are due in part to the topography of the pecking response: Pecking is the consummatory response in pigeons. With other organisms (e.g., rats), the response to be autoshaped (e.g., leverpress) is not linked directly to the organism's consummatory response. There is also evidence to support the contention that the pigeon's autoshaped keypeck is more strongly controlled by stimuli in autoshaping procedures than are other organisms' responses. Pigeons in either a negative-automaintenance (Williams \& Williams, 1969) or a signal-controlled-responding (Dougherty \& Lewis, 1991a; Lewis \& Stoyak, 1979) paradigm will continue to re- 
spond during a brief stimulus that precedes a reinforcer after being autoshaped (or handshaped), in spite of an omission contingency whereby responses cancel the delivery of many reinforcers. Some other organisms will not continue to respond given the same omission contingencyfor example, crows (Powell \& Kelly, 1976), guinea pigs (Poling \& Poling, 1978), and squirrel monkeys (Gamzu \& Schwam, 1974). These species differences in the strength of control by autoshaping stimuli may have played a role in our inability to autoshape horses.

\section{REFERENCES}

Brown, P. L., \& Jenkins, H. M. (1968). Autoshaping of the pigeon's keypeck. Journal of the Experimental Analysis of Behavior, 11, 1-8.

DOUGHeRTY, D. M. (1990). Meeting novel experimental needs with an Apple Pascal controlled interfacing system. Behavior Research Methods, Instruments, \& Computers, 22, 533-539.

DOUGHERTY, D. M., \& LEWIS, P. (1991a). Elicited responding in chain schedules. Journal of the Experimental Analysis of Behavior, 56, 113-140.

DougherTy, D. M., \& LEWIS, P. (1991b). Stimulus generalization, discrimination learning, and peak shift in horses. Journal of the Experimental Analysis of Behavior, 56, 97-104.

DougherTy, D. M., LeWIS, P. (1992). Matching by horses on several concurrent variable-interval schedules. Behavioural Processes, 26, 69-76.

Fleshler, M., \& Hoffman, H. S. (1962). A progression for generating variable-interval schedules. Journal of the Experimental Analysis of Behavior, 5, 529-530.

GamzU, E., \& Schwam, E. (1974). Autoshaping and automaintenance of a keypress response in squirrel monkeys. Journal of the Experimental Analysis of Behavior, 21, 361-371.

GARDNER, W. M. (1969). Autoshaping in bobwhite quail. Journal of the Experimental Analysis of Behavior, 12, 279-281.
LeWis, P., Stoyak, M. (1979). Signal-controlled responding. Journal of the Experimental Analysis of Behavior, 31, 115-125.

MoOre, B. R. (1973). The role of directed Pavlovian reactions in simple instrumental learning in the pigeon. In R. A. Hinde \& J. StevensonHinde (Eds.), Constraints on learning (pp. 159-188). New York: Academic Press.

Peterson, G. B., Ackil, J. E., Frommer, G. P., \& Hearst, E. S. (1972). Conditioned approach and contact behavior toward signals for food or brain-stimulation reinforcement. Science, 177, 1009-1011.

Poling, A., \& Poling, T. (1978). Automaintenance in guinea pigs: Effects of feeding regimen and omission training. Journal of the Experimental Analysis of Behavior, 30, 37-46.

Powell, R. W., \& Kelly, W. (1976). Responding under positive and negative response contingencies in pigeons and crows. Journal of the Experimental Analysis of Behavior, 25, 219-225.

Schwam, E., \& GamzU, E. (1975). Constraints on autoshaping in the squirrel monkey: Stimulus and response factors. Bulletin of the Psychonomic Society, 5, 369-372.

Schwartz, B., \& Gamzu, E. (1977). Pavlovian control of operant behavior: An analysis of autoshaping and its implications for operant conditioning. In W. K. Honig \& J. E. R. Staddon (Eds.), Handbook of operant behavior (pp. 53-97). Englewood Cliffs, NJ: Prentice-Hall.

SмITH, S. G., \& SMITH, W. M., JR. (1971). A demonstration of autoshaping with dogs. Psychological Record, 21, 215-221.

SQuier, L. H. (1969). Autoshaping key responses with fish. Psychonomic Science, 17, 177-178.

Williams, D. R., \& Williams, H. (1969). Automaintenance in the pigeon: Sustained pecking despite contingent non-reinforcement. Journal of the Experimental Analysis of Behavior, 12, 511-520.

(Manuscript received November 9, 1992.) 